\title{
The Spatio-temporal Evolution of Economic Network Structure in Guanzhong Plain Urban Agglomeration
}

\author{
Song Qiong \\ College of Urban and Environmental Sciences \\ Northwest University \\ Xi'an710127, China
}

\author{
Han Jing \\ College of Urban and Environmental Sciences \\ Northwest University \\ Xi'an710127, China
}

\author{
Li Tongsheng* \\ College of Urban and Environmental Sciences \\ Northwest University \\ Xi'an710127, China
}

\begin{abstract}
The spatial and temporal evolution characteristics of network structure of Guanzhong Plain urban agglomeration from 2005 to 2015 are analyzed from the economic perspective by using the modified gravity model and the SNA method. Results show that: (1) Economic network of urban agglomeration has experienced the evolution from the primary to intermediate phase. The backbone network is composed of Xi'an, Tongchuan, Xianyang, Baoji, Weinan, taking Xi'an as the center, with the axis to develop Lanzhou-Lianyungang. (2) During 10 years, although radiation and agglomeration intensity of 12 cities increase significantly, the polarization difference between the first city and the last one is also expanding. (3) The network hierarchy of urban agglomeration needs to be improved. Only $\mathrm{Xi}^{\prime}$ an has the strong radiation-driven ability among the 12 cities, while Baoji as the central city of the western region is weak. (4) Affected by geographical locations, cities with intermediate interests are mostly located in the central region, and 6 peripheral cities have not yet obtained intermediary interests.
\end{abstract}

Keywords-Guanzhong Plain urban agglomeration; Economic network; Spatio-temporal evolution; SNA

\section{INTRODUCTION}

The foreign study of urban network in the human and economic geography is relatively early [1], after the 1990s, it gradually formed the research paradigm of "urban network" based on the relationship. At present, the domestic research on urban network is in the flourishing stage of "a hundred flowers blossom and a hundred schools of thought contend". The research area by focusing on eastern urban metropolitan [2] extending to the central and western urban agglomeration [3-4], the research scale is characterized by the synchronous development of national macro [5], regional meso [6] and urban microcosmic [7]. The research contents include enterprise [8], traffic [9], information [10], tourism [11] and so on.

The Guanzhong plain urban agglomeration is located at the intersection of the land bridge channel and the Baotou- Kunming channel in the national main function area planning, which is typical representative in the central and western urban agglomeration of the country. With the help of the revised gravity model and social network analysis method, this paper analyzes the temporal and spatial evolution characteristics of the Guanzhong Plain urban agglomeration in 2005-2015 years from the perspective of economic relations, which is beneficial to optimize the spatial organization path of the urban agglomeration and give full play to the potential of the region.

\section{DATA AND METHODS}

\section{A. Data}

The Guanzhong plain urban agglomeration occupies for $1.12 \%$ of China's total land area, with a total area of 107 thousand $\mathrm{km} 2$. According to "the Guanzhong Plains Urban Agglomeration Development Plan", which covers areas including Xi'an, Baoji, Xianyang, Tongchuan, Weinan, Yangling agricultural high-tech industrial demonstration area of Shaanxi Province all domain, as well as parts of districts and counties in Shangluo of Shaanxi Province, Yuncheng and Linfen of Shanxi Province, Tianshui, Pingliang and Qingyang in Gansu province (FIG.I). The paper takes 12 urban districts as the research unit, using population, social and economic data from the "China City Statistical Yearbook" from 2006 to 2016. All indicators of Yangling are derived from the 2006-2016 "Shaanxi Statistical Yearbook" and the "Statistical Bulletin of Yangling Demonstration Area". The spatial distance comes from the Intergovernmental highway mileage of Baidu maps.

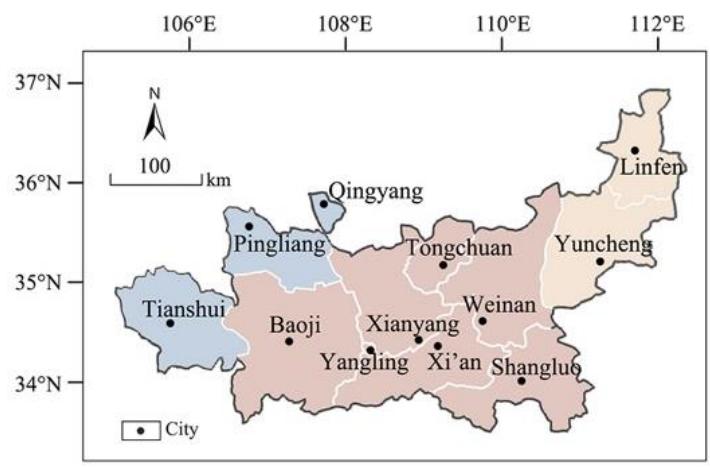

Fig. 1 Study areas 


\section{B. Methods}

(1)Modified gravity model.

The total economic volume is the primary index for measuring the quality of the city. As the main body and objective carrier of the activity, population and land area are also important indicators to evaluate the urban linkage. The empirical constant is corrected by the ratio of a single city's quality to the sum of two cities' quality. The revised formula [12] is:

$$
F_{i j}=\frac{E_{i}}{E_{i}+E_{j}} \times \frac{\sqrt[3]{E_{i}} \times \sqrt[3]{E_{j}}}{D_{i j}^{2}}, E_{i}=S_{i} P_{i} G_{i}, E_{j}=S_{j} P_{j} G_{j}
$$

In the formula, $F_{i j}$ is the connection value between $i$ and $j$ city; $E_{i}$ and $E_{j}$ are the quality of city $i$ and $j ; S$ is the construction land area, $P$ is the total population, $G$ is the economic aggregate, and $D_{i j}$ is the spatial distance of cities.

(2) Social network analysis method.

1) Network Density. Network density reflects the density of the network connection as a whole. The calculation formula ${ }^{[13]}$ is

$$
D=\sum_{i=1}^{k} \sum_{j=1}^{k} \frac{d\left(n_{i}, n_{j}\right)}{k(k-1)}
$$

In the formula, $D$ is the network density, $K$ is the number of cities, $d\left(n_{i}, n j\right)$ is the relationship between cities.

2) Degree centrality. The degree centrality is the sum of the relationship between city $\mathrm{A}$ and all other cities. It is divided into outdegree and indegree. The calculation formula ${ }^{[13]}$ is

$$
C\left(n_{i}\right)=\sum_{j=1}^{n} X_{i j}
$$

In the formula, $C\left(n_{i}\right)$ is outdegree or indegree, $X_{i j}$ indicates the connection value of the cities $i$ and $j$.

3) Betweenness centrality. The betweenness centrality characterizes the ability of a city to control the interaction between other cities in the network, namely "intermediary". Calculation formula ${ }^{[13]}$ is

$$
C_{B}\left(n_{i}\right)=\sum_{j<k} \frac{g_{j k}\left(n_{i}\right)}{g_{j k}}
$$

In the formula, $C_{B}\left(n_{i}\right)$ is betweenness centrality, $g_{i k}$ is the shortest path number of the city $j$ to $k, g_{j k}\left(n_{i}\right)$ is the number of shortest paths through city $i$ to make city $j$ link with $k$.

\section{EVOLUTION CHARACTERISTICS OF ECONOMIC Network In GuANZHONG Plain URban AgGlOMERATION}

\section{A. Evolution characteristics of network connection}

The interaction intensity of Guanzhong plain urban agglomeration in 2005, 2010 and 2015 was calculated by the modified gravity model. The SNA method was used to estimate the evaluation indexes of urban network. In order to better reflect the evolution trend, the linkages of $<1$ were not shown in the map (FIG.II). According to the principle of large difference between groups, small difference in the group was divided into five levels by the 2005 contact value: Level I contact $(>42.67)$, level II contact (18.91 42.67), level III contact (5.38 19.53), level IV contact (2.97 5.38), and level V contact (1.00 2.97).
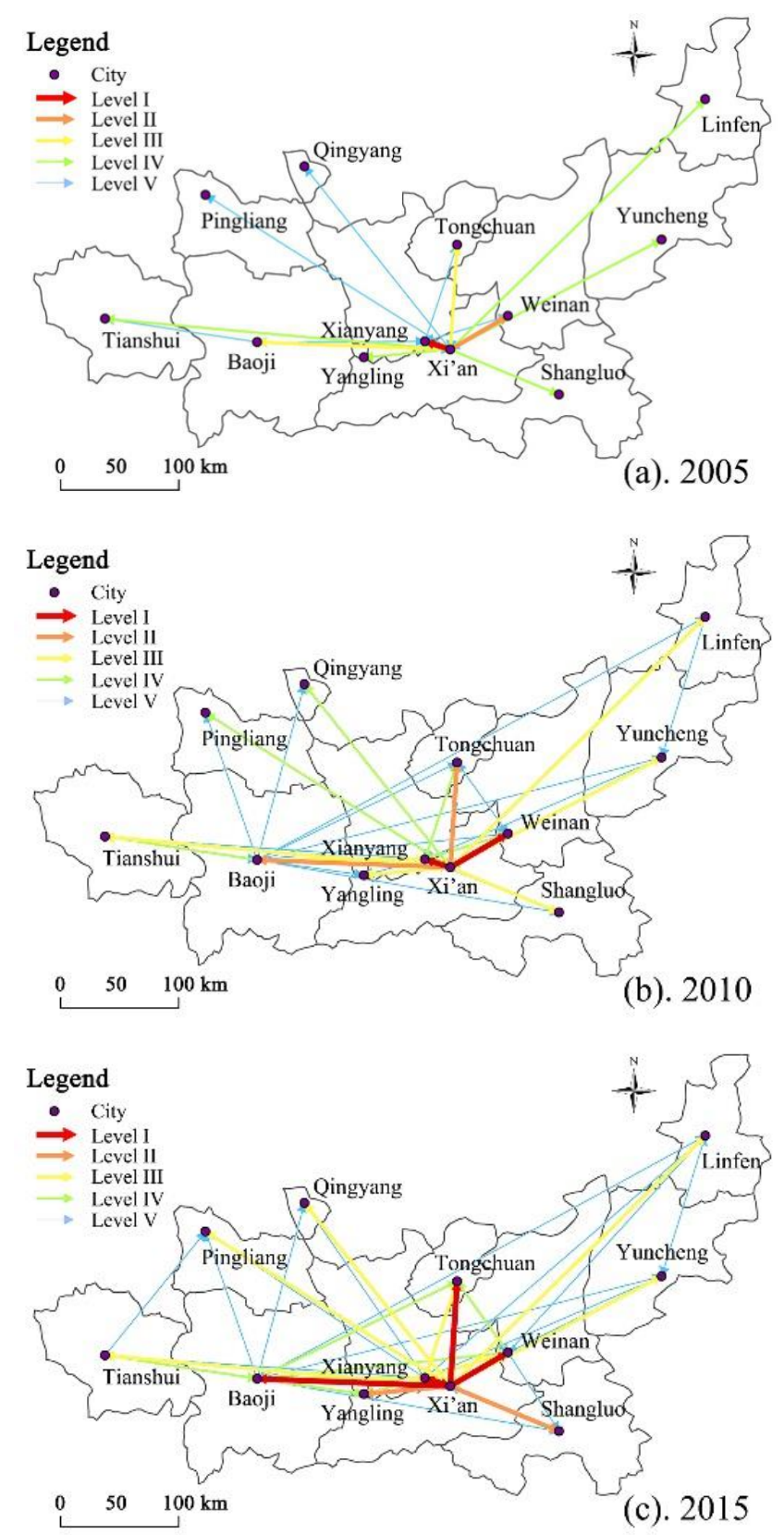

Fig. 2 The spatial relation of economic networks in guanzhong plain urban agglomeration from 2005 to 2015

In 2005, there were 21 connection lines in the economic network of the Guanzhong plain urban agglomeration. The network density was 0.159 and the connection was loose. Urban agglomeration only have one line in level I and level II, and there are four connection lines in level III ,five contact lines in level IV and ten relation lines in level V. According to FIG.II, found that: First, radiation force of Xi'an covers 11 other cities, and the maximum network connection is $\mathrm{Xi}^{\prime}$ an $\rightarrow$ Xianyang (60.19). Second, the first and second level relation in the network is the radiating of Xi'an, which connects nearby cities along the Lianyungang-Lanzhou axis. Third, the level III links mainly shows the radiating effect from Xi'an to the cities in Shaanxi province and the feedback effect from Xianyang to 
Xi'an. Four, Level IV relation are mainly present as radiating effect from Xi'an to other cities in Shanxi and Gansu Province. Five, the level $\mathrm{V}$ contact lines accounts for $47.6 \%$, mainly showing the radiation effects of Baoji and Xianyang on the cities and the agglomeration of Xi'an on the cities in Shaanxi province.

In 2010, there were 40 connection lines of economic network in the Guanzhong plain urban agglomeration, with a density of 0.303, and the network was in a rapid growth stage. The radiative capacity of Xi'an and Baoji covers all the cities. Firstly, there are two contact lines in level I: Xi'an $\rightarrow$ Xianyang (143.18), Xi'an $\rightarrow$ Weinan (42.68), and 3 lines in level II: Xi'an $\rightarrow$ Tongchuan (39.06), Xi'an $\rightarrow$ Baoji (34.76), Xianyang $\rightarrow X i$ 'an (25.70), it showed as the radiation from Xi'an to adjacent cities. Secondly, there is total amount of eight of level III and 7 lines of level IV, which are mainly reflected in the radiation of Xi'an to the peripheral cities of the urban agglomeration and the gathering of other cities by Xi'an in Shaanxi province. Thirdly, there is total amount of 20 in level $\mathrm{V}$, which takes a proportion of $50 \%$, indicating that the contact volume of the Guanzhong plain urban agglomeration is increasing, but the contact is mainly weak. At this time, it is mainly for the external radiation of Baoji and Xianyang and the interaction between neighboring cities. Fourth, the economic network is composed of radial backbone networks from Xi'an, Xianyang, Weinan, Baoji and Tongchuan, with Xi'an as the center and along the axis of the Lianyungang-Lanzhou.

In 2015, there were 55 lines in economic network of the urban agglomeration, with a density value of 0.417 , and the network developed to an intermediate stage. Firstly, level I connection line has increased to a total amount of 5, and all the radiating links from Xi'an to Xianyang, Weinan, Tongchuan and Baoji all come up to level I in the backbone network, which means the economic network of urban agglomeration is well developed and the structure of backbone network is stable. Secondly, Xi'an completed the coverage of the cities in Shaanxi province at level II, and Xi'an completed the radiation coverage of the whole city group at the level III contact. The level IV linkage is mainly manifested by the outward radiation of Baoji and the interaction between neighboring cities in Shaanxi province. The level $\mathrm{V}$ links are mainly the radiation effects of Baoji, Xianyang and Weinan on remote cities.

\section{B. Evolution characteristics of node cities}

\section{(1) Change of Degree Centrality}

The degree centrality reflects the capacity of urban radiation and gathering (TAB.I). First, the indegree and outdegree of each city has been greatly improved, but the degree of polarization is also expanding. The extreme degree of extroversion increased from 138.59 to 609.88 , and the degree of introversion increased from 60.63 to 278.13 . Second, due to the external contact is below the threshold, the number of cities dominated by agglomeration was reduced from 7 to 3 . Third, only Xi'an is the city with strong radiative power for the whole time, The gathering ability of remaining 11 cities is stronger than the radiation capacity, Baoji as a regional central city driving capacity is weak, so the hierarchy characteristics of economic network is not obvious.

TABLE I THE DEGREE CENTRALITY OF ECONOMIC NETWORKS

\begin{tabular}{ccccccc}
\hline & \multicolumn{2}{c}{$\mathbf{2 0 0 5}$} & \multicolumn{2}{c}{$\mathbf{2 0 1 0}$} & \multicolumn{2}{c}{$\mathbf{2 0 1 5}$} \\
\cline { 2 - 6 } Cities & $\begin{array}{c}\text { Out } \\
\text { Degree }\end{array}$ & $\begin{array}{c}\text { In } \\
\text { Degree }\end{array}$ & $\begin{array}{c}\text { Out } \\
\text { Degree }\end{array}$ & $\begin{array}{c}\text { In } \\
\text { Degree }\end{array}$ & $\begin{array}{c}\text { Out } \\
\text { Degree }\end{array}$ & $\begin{array}{c}\text { In } \\
\text { Degree }\end{array}$ \\
\hline Xi'an & 138.59 & 17.20 & 320.11 & 44.38 & 609.88 & 77.38 \\
Tongchuan & 1.94 & 19.52 & 7.29 & 46.61 & 13.05 & 83.90 \\
Baoji & 5.07 & 13.19 & 32.07 & 41.26 & 42.54 & 70.06 \\
Xianyang & 15.32 & 62.88 & 43.12 & 152.88 & 77.86 & 291.44 \\
Weinan & 3.37 & 21.24 & 9.43 & 50.53 & 25.33 & 105.79 \\
Shangluo & 0 & 5.38 & 0 & 14.58 & 1.07 & 27.74 \\
Yangling & 0 & 4.31 & 0 & 15.51 & 0 & 29.64 \\
Yuncheng & 0 & 5.03 & 0 & 14.01 & 3.79 & 24.53 \\
Linfen & 0 & 4.60 & 1.05 & 8.98 & 2.78 & 19.46 \\
Tianshui & 0 & 5.76 & 2.95 & 14.52 & 7.80 & 26.12 \\
Pingliang & 0 & 2.97 & 0 & 6.29 & 0 & 14.72 \\
Qingyang & 0 & 2.25 & 0 & 6.47 & 0 & 13.31 \\
\hline
\end{tabular}




\section{(2) Change of Betweenness Centrality}

The Betweenness Centrality reflects the ability of the city to gain intermediary benefits (TAB.II). Firstly, over time, the number of cities that obtain intermediary interests in urban agglomeration has increased from 3 to 5. The polarization gap between the first and the last cities showed a trend of first decline and then rise, From 31.5 in 2005 decreased to 14.17 in 2010, then rose to 29.33 in 2015 . Secondly, Xi'an has always been the city with the largest intermediary interest, while Baoji overtook Xianyang in 2010 and remained in second place in 2015. Thirdly, the size of intermediary interests is closely related to geographical location. Cities that have obtained intermediary benefits are in the middle position. However, Tongchuan, Shangluo, Linfen, Tianshui, Pingliang and Qingyang which is located in the periphery have not gain any intermediary interest for 10 years.

TABLE II THE BETWEENNESS CENTRALITY OF ECONOMIC NETWORKS

\begin{tabular}{cccc}
\hline Cities & $\mathbf{2 0 0 5}$ & $\mathbf{2 0 1 0}$ & $\mathbf{2 0 1 5}$ \\
\hline Xi'an & 31.5 & 14.17 & 29.33 \\
Tongchuan & 0 & 0 & 0 \\
Baoji & 0.5 & 8.83 & 5.33 \\
Xianyang & 2 & 3.67 & 5.33 \\
Weinan & 0 & 0.33 & 3.5 \\
Shangluo & 0 & 0 & 0 \\
Yangling & 0 & 0 & 0 \\
Yuncheng & 0 & 0 & 0.5 \\
Linfen & 0 & 0 & 0 \\
Tianshui & 0 & 0 & 0 \\
Pingliang & 0 & 0 & 0 \\
Qingyang & 0 & 0 & 0
\end{tabular}

\section{CONCLUSION AND DISCUSSION}

\section{A. Conclusion}

This paper selects the 2005, 2010 and 2015 as time nodes, by using the methods of modified gravity model and SNA, analyzes the economic network structure of urban agglomeration in Guanzhong plain agglomeration from the network connection and urban node. The conclusion is as following: (1) Economic network of urban agglomeration has completed the rapid growth from the initial stage to the intermediate stage. The urban agglomeration is dominated by the radiation from the central city of $\mathrm{Xi}^{\prime}$ an, and the clustering features are not obvious. (2) The backbone network of urban agglomeration takes Xi'an as the center, along the LianyungangLanzhou axis, forms a stable radial structure that composed of Xi'an, Xianyang, Baoji, Weian and Tongchuan. (3) Baoji gradually grew into the central city of the western region, while the eastern regional center city was still in the competition stage. (4) There is a significant increase in the ability of radiating and gathering of 12 cities in the urban agglomeration. However, the degree of polarization was also increasing. The city with strong driving ability is always only Xi'an. Baoji as a central city in western region is weak in driving force. The hierarchy of the entire network needs to be optimized. (5) There are more and more cities to obtain intermediary interest, but the peripheral cities still have not breached the geographical limit to obtain intermediary benefits.

\section{B. Discussion}

The economic network of the Guanzhong plain urban agglomeration is at the intermediate stage to the advanced stage in currently, and the hierarchical features of network is not obvious. Xi'an's urban primacy ratio is extremely high. Regional central cities have limited in driving ability. And the central city of eastern region is not clear. Above all of these will influence the urban agglomerations to evolve into a higher stage. Analyzing the internal driving mechanism of urban agglomeration economic network and optimizing spatial organization path will become the direction of further research.

\section{REFERENCES}

[1] Bao C, Chen X J. Review and prospect of research on the spatial pattern of China's urban system. Progress in Geography, 2014, 33(10):1300-1311. (In Chinese)

[2] Zhao M X, Wei J M, Wu K. Functional Linkages in the Beijing-TianjingHebei Conurbation Region and Evolution of the Complex Networks [J]. Urban Planning Forum, 2014, (1):46-52. (In Chinese)

[3] Sun Q, Tang F H, Tang Y. An economic tie network-structure analysis of urban agglomeration in the middle reaches of Changjiang River based on SNA [J]. Journal of Geographical Sciences, 2015, 25(6):739-755. (In Chinese)

[4] Tan Y M, Yang Y C, Leng B R, Li T T.Urban Network System in Chengdu-Chongqing Region in the Perspective of Advanced Producer Service[J]. Progress in Geography, 2011, 30(6):724-732. (In Chinese)

[5] Chen W, Liu W D, Ke W Q et al. The spatial structures and organization patterns of China's city networks based on the highway passenger flows [J]. Acta Geographica Sinica, 2017, 72 (2):224-241. (In Chinese)

[6] Li T, Zhou R. Urban hinterworld in Yangtze River Delta: Empirical comparison of two network-based methods [J]. Acta Geographica Sinica, 2016, 71(2):236-250. (In Chinese)

[7] Chang E Y, Zhen F, Sun C. Use of community networks and its impact on community participation: A case study of Nanjing City [J]. Progress in Geography, 2017, 36(7): 785-794. (In Chinese) 
[8] Wu K, Fang C L, Zhao M X. The spatial organization and structure complexit of Chinese intercity networks [J]. Geographical Research, 2015 , 34(4):711-728. (In Chinese)

[9] Wang J E, Jing Y. Comparison of spatial structure and organization mode of inter-city networks from the perspective of railway and air passenger flow [J]. Acta Geographica Sinica, 2017, 72 (8):1508-1519. (In Chinese)

[10] Wang B, Zhen F. Impacts of City's Characteristics on City's Importance in the Virtual World: An Empirical Analysis Based on Internet News Media. Scientia Geographica Sinica, 2017, 37(8):1127-1134. (In Chinese)

[11] Gao P, Xi J C. Research on the Spatial Structure and Complex Characteristics of Tourism Destination Network - A Case Study of Yesanpo Tourism Destination [J]. Journal of Natural Resources, 2018, 33(1): 85-98. (In Chinese)

[12] Zhong Y X, Feng X H, Wen Y Z. The Evolvement and Driving Mechanism of Economic Network Structure in the Changjiang River Economic Zone [J]. Scientia Geographica Sinica, 2016, 36 (1):10-19. (In Chinese)

[13] Liu J. Overall network analysis notes: UCINET software practical guide [M]. Shanghai: Truth \& Wisdom Press.2009. (In Chinese) 